\title{
The Social-Emotional Learning Process to Develop Practicing Skills for Hands-on Students
}

\author{
Kridsanapong Lertbumroongchai, Kobkiat Saraubon, and Prachyanun Nilsook
}

\begin{abstract}
The purpose of this research is to synthesize the social-emotional learning process to develop practicing skills for hands-on students, to develop the process, and to evaluate the process. In this study, the documentary research method and in-depth interview method were employed. The results showed that the synthesis of the social-emotional learning process to develop practicing skills for hands-on students consisted of six steps: 1) perception is divided into sensory perception and explaining perceived, 2) observation is divided into certain goals, discretion, notes, observations, and time limit, 3) analysis and brainstorming is divided into information, brainstorming, and discovering new knowledge, 4) practicing is divided into cognitive phase, associative phase, and autonomous phase, 5) checking and improvement is divided into opinion, learning exchange, and providing opportunities, and 6) action is divided into behavior changing, and application of academic knowledge. Evaluating the social-emotional learning process to develop practicing skills for hands-on students employed in-depth interview technique consisting of 21 experts in three different areas (i.e., in learning and teaching, information technology, and mass communication technology terms). The results of the suitability evaluation revealed that the social-emotional learning process model with mixed reality for the hands-on students was at the highest level.
\end{abstract}

Index Terms-Learning process, social-emotional learning, practicing skills.

\section{INTRODUCTION}

In the present, there is something rather than academic content. A person who can succeed in learning and working must be able to adapt, respect others, be honest, and communicate with others well [1] and [2]. Nowadays, learners have digital learning methods and use digital devices to inquire knowledge, communicate, and work with others. Educational institutions must create an environment for learners to have a learning process that they can coexist with others, train the learners to work with others, have responsibility for themselves and others, know and understand the feelings of others, and participate with others.

Based on the research, it was found that the Social Emotional Learning (SEL) can help to change the attitudes and behaviors of the social emotions of learners in a positive way, prevent risks, and correct behavioral problems of

Manuscript received December 9, 2019; revised March 2, 2020.

Kridsanapong Lertbumroongchai and Prachyanun Nilsook are with Division of Information and Communication Technology for Education, Faculty of Technical Education, King Mongkut's University of Technology North Bangkok, Thailand (e-mail: kridsanapong_1@rmutt.ac.th, prachyanunn@kmutnb.ac.th).

Kobkiat Saraubon is with Department of Computer and Information Science, King Mongkut's University of Technology, North Bangkok, Thailand (e-mail: kobkiat.s@sci.kmutnb.ac.th). learners effectively. In addition, it is able to create positive health effects, increase interest in learning, the face of disappointment, troubleshooting, and adaptation of living with others in society. Social-emotional learning consists of five elements: Self-Awareness, Social Awareness, Self-Management, Responsible Decision Making, and Relationship Skills [3]-[5]. The learners through social-emotional learning will have digital emotional intelligence immunity, are able to cope with the problems that occur in the digital world, such as conflicts in the digital world, cyberbullying, and so on. In addition, they have to be able to prevent potential mental health problems from the digital world [3], [6]-[8].

In this present research, social-emotional learning process was created from the synthesis of documents and research related to social learning and emotional learning. Social learning is an important learning that changes attitudes because humans have collaborative learning in society and always interact with the environment. Learning is created from observation or imitations of behavior, attitudes, and values consisting of four processes: 1) attentional process, 2) retention process, 3) motor reproduction process, and 4) motivational process. For attention, we cannot learn if we do not focus on the task. If we create interesting social contexts, social contexts help to reinforce these perceptions and create attention of the learners. For retention, we learn by internalizing information in our memories. We recall that information later when we are required to respond to a situation that is similar to the situation in which we first learned the information. For reproduction, we reproduce previously learned information (e.g., behavior, skills, and knowledge) when required. However, practicing through mental and physical rehearsal often improves our responses. For motivation, we need to be motivated to do anything. Motivation originates from our observation of someone else being rewarded or punished for something they have done or said. This usually motivates us later to do or avoid doing the same thing.

Emotional learning is a learning process that can change behavior which is a basic life skill because education must link academic knowledge to specific skills. To be successful in living with others, such as in educational institutions, family, communities, and workplaces, students must have self-control skills and a moral which is important to the world in the present and future. This consists of four processes as follows [9]: 1) emotion and stress management, 2) good relationship creation, 3) awareness and appreciation in oneself and others, and 4) the analysis thinking. For emotion and stress management, the emotion is important to show who we are and how we relate to other people. 
Understanding the emotions expressed in creative ways will help to resolve conflicts and develop characteristics. Helping the learners to communicate the feelings and know how to respond to other people's emotions is necessary. This help to better understand their friends and themselves. The emotional management skills that the learners should develop are, for example, expressing the feelings, empathizing with others ability, understanding various situations, and rejecting of provocation. For good relationship creation, good relationship is necessary to have a mutual trust which uses time, physical power, and determination to maintain that relationship. Creating the mutual trust must develop skills, such as respecting others, sympathizing, communicating, collaborating, and negotiating with others in a problematic situation. For awareness and appreciation in oneself and others, if children and young people learn to realize and appreciate themselves and others, they will grow up to become adults with self-confidence and high potential. In order to see the value of others, they must see inside others' hearts rather than their appearances. If we want to live in a world that has peace and harmony, we have to appreciate and praise things that are different from us as well as ourselves. To help children and youths to see their own values and others is necessary to develop many abilities, such as respecting others to achieve the belief that others deserve mercy and compassion as part of sharing with friends. Appreciation of diversity in order to understand that individual diversity is a component that makes another part complete and recognition of various strengths to discover and develop each person's positive attributes. For the analysis thinking, making decisions, and solving problems creatively, in the lives of people, we find many choices daily. It can be said that our character will show from the choices we have chosen. The choices and decisions that we have made every day are all determined by our character whether we are aware or not. This character of our own will determine our lives. For solving problems and making effective decisions, students should know what they should think, not just thinking anything. Problem-solving and decision-making skills, as well as other life skills, will develop according to time and experience. The children and youths will be able to learn how to solve problems and make effective decisions. They must have developed the following skills, such as expressing ethic, determining goals and planning, asking for help, having a responsibility, and rejecting of provocation.

Strategies for producing hands-on students of Rajamangala University of Technology Thanyaburi 20 years 2017-2036 want to produce hands-on student work as required by the establishment. The social-emotional learning process will develop the learners to become hands-on students. Fitts (1964) gives advice on the development of skillful actions that will occur according to the 3-step skills development process. First, the cognitive phase is a step that tells the skills and knowledge of relevant theories which instructors should provide information to students in various areas, including what to do and what you need to see and avoid. For example, you need to know the process that requires for work, what precautions should be taken, and the desired standard level. Students should pay special attention to analyzing various errors. This understanding should be done in a short period of time. Second, the associative phase is an action to get behavior in the correct format. Skills can be achieved when operating. Incorrect errors or behaviors should be limited. In this process, instructors should arrange activities for students in various areas, including demonstrating skills to practice. This allows students to mimic skills, practice that skill with real situations and simulations, provide knowledge and information about the effects of skills, and provide advice and assistance as needed. This step should be started from the cognitive stage and should be contacted periodically. Third, the autonomous phase is a process that is fast and accurate. The opportunity to make a mistake will not happen. Skills increased will lead to the expertise. It is more automated at this stage, and we call the expert stage which requires a lot of practice. Training in this stage is considered to have reached the final level of the taxonomy in the range of skills. In this stage, the instructor should arrange activities for the students to do in various areas, including more skill training, learning how to overcome stress, increasing speed and accuracy, and achieving the desired standard experience at this stage. Each student may show different achievements. This difference often depends on the abilities, interests, habits, emotions, and perseverance of the learner. The characteristics of graduate practitioners include practice, application of theories, application of academic and professional knowledge, and product creations [10]. In addition, the learner must have digital emotional intelligence which means being able to build good relationships with others through digital media, such as caring for others and showing kindness, and helping others in the online world. It is divided into 3 elements: empathy, emotional awareness and regulation, and social and emotional awareness. The digital emotional intelligence has five performance areas: perceive, understand, use, manage, and connect [11]. Social-emotional learning will help learners to create digital emotional intelligence.

Therefore, the researcher aims to develop the social-emotional learning process to develop practicing skills for hands-on students and to develop the process to make a concept and guideline for the development of mixed reality media for learning and developing hands-on students according to the 20 years (2017-2036) Policy of the Rajamangala University of Technology Thanyaburi.

\section{PURPOSE}

1) To synthesize the social-emotional learning process to develop practicing skills for hands-on students.

2) To develop the social-emotional learning process to develop practicing skills for hands-on students.

3) To evaluate the social-emotional learning process to develop practicing skills for hands-on students.

\section{SCOPE OF STUDY}

This research is documentary research and then developed into the social-emotional learning process model with mixed reality for hands-on students by using in-depth interview method. The In-depth interview was conducted with 21 
experts in three different areas (i.e., in learning and teaching, information technology, and mass communication technology terms). These experts have had experience in related fields more than 3 years.

\section{MethodolOGY}

The development of the social-emotional learning process to develop practicing skills for hands-on students, divided research into 3 phases according to the research objectives as follows:

Phase 1: Study documents and research and synthesis the social-emotional learning process to develop practicing skills for hands-on students.
Phases 2: Develop the social-emotional learning process to develop practicing skills for hands-on students.

Phases 3: Evaluate the social-emotional learning process to develop practicing skills for hands-on students.

\section{RESUlts OF A RESEARCH}

\section{A. Synthesis of Emotional and Social Learning Processes}

The researcher studied the documents and research related to social-emotional learning and synthesis of processes. The results are as shown in Table I.

TABLE I: SYNTHESIS OF EMOTIONAL AND SOCIAL LEARNING PROCESSES

\begin{tabular}{|c|c|c|c|c|c|c|c|c|c|}
\hline \multirow{2}{*}{ Social Emotional Learning } & \multicolumn{4}{|c|}{ Social Learning } & \multicolumn{4}{|c|}{ Emotional Learning } & \multirow[t]{2}{*}{ The Researcher } \\
\hline & {$[12]$} & [13] & [14] & [15] & [9] & {$[16]$} & [17] & {$[18]$} & \\
\hline \multicolumn{10}{|l|}{ 1. Perception } \\
\hline 1.2 Explaining Perceived & $\checkmark$ & $\checkmark$ & $\checkmark$ & $\checkmark$ & $\checkmark$ & $\checkmark$ & $\checkmark$ & & $\checkmark$ \\
\hline \multicolumn{10}{|l|}{ 2. Observation } \\
\hline 2.1 Certain Goals & & & $\checkmark$ & $\checkmark$ & $\checkmark$ & & & $\checkmark$ & $\checkmark$ \\
\hline 2.3 Notes & & & $\checkmark$ & $\checkmark$ & $\checkmark$ & & & $\checkmark$ & $\checkmark$ \\
\hline 2.4 Observations & & & $\checkmark$ & $\checkmark$ & $\checkmark$ & & & $\checkmark$ & $\checkmark$ \\
\hline 2.5 Time Limit & & & $\checkmark$ & $\checkmark$ & $\checkmark$ & & & $\checkmark$ & $\checkmark$ \\
\hline \multicolumn{10}{|l|}{ 3. Analysis and Brainstorming } \\
\hline 3.1 Information & $\checkmark$ & & $\checkmark$ & $\checkmark$ & $\checkmark$ & & $\checkmark$ & $\checkmark$ & $\checkmark$ \\
\hline 4.2 The associative phase & & $\checkmark$ & & $\checkmark$ & & & $\checkmark$ & $\checkmark$ & $\checkmark$ \\
\hline 4.3 The autonomous phase & & $\checkmark$ & & $\checkmark$ & & & $\checkmark$ & $\checkmark$ & $\checkmark$ \\
\hline \multicolumn{10}{|l|}{ 5. Checking and Improvement } \\
\hline 5.1 Opinion & $\checkmark$ & & & & $\checkmark$ & $\checkmark$ & & & $\checkmark$ \\
\hline 5.2 Learning Exchange & $\checkmark$ & & & & $\checkmark$ & $\checkmark$ & & & $\checkmark$ \\
\hline 5.3 Providing Opportunities & $\checkmark$ & & & & $\checkmark$ & $\checkmark$ & & & $\checkmark$ \\
\hline \multicolumn{10}{|l|}{ 6. Action } \\
\hline 6.1 Behavior Changing & $\checkmark$ & $\checkmark$ & $\checkmark$ & & & $\checkmark$ & & & $\checkmark$ \\
\hline 6.2 Application of Academic Knowledge & $\checkmark$ & $\checkmark$ & $\checkmark$ & & & $\checkmark$ & & & $\checkmark$ \\
\hline
\end{tabular}

From Table I, according to the synthesis of literature review related social-emotional learning process for hands-on students is shown in Fig. 1, there are 6 steps as follows.

1) Perception is the first step consisting of:

a) Sensory Perception: The perception is made through the five senses, including vision, hearing, smell, taste, and external organs. This is a cognitive process that results from behavior and the attitude of the person. The perception of each person varies according to the experience they receive.

b) Explaining Perceived: This makes the interpretation and response to the information received differently because individuals will be assessed by their own experience and background. Perception affects feelings. When the organ is exposed to stimuli and passes through the nerves into the brain, it will cause feelings in various energy forms, such as heat, light, and sound, so on. Each organ will receive different energy, such as eyes, light perception, sound recognition, ear, nose, smell recognition, tongue to taste, and the skin perceiving the temperature. The organ will transform data through the nervous system, traveling up to the brain.
The brain will feel like seeing and hearing. However, if there is an interpretation, it is called perception, such as indicating what the eye sees, what sound is heard, the smell received, and so on. The identification of stimuli shows that the person has experience knowing things before.

2) Observation is a method of collecting information that is caused by observing various things. Observations may occur by recording in order to use the information obtained to be analyzed as knowledge. Good observations must be sensitive to the perception and meaning with careful and observant resolution with the intention of observing and neutral. Observational principles are as follows.

a) Certain goals: Observers must determine the purpose of observation. Once the objective has been achieved, observers should also determine the issue of observation to get the information that meets the needs of most observers. They may create an observation form for recording information in the event that there is a lot of information.

b) Discretion: Observers must have a judgment in giving meaning to what they observe. The information received must be carefully considered before using the data. 
c) Notes: Observers should create an observation form from the objectives and issues in order to facilitate data analysis. The record format may be open-ended or closed-ended questions, but they must be relevant to the objectives of the observation.

d) Observations: Observers should collect information from multiple sources so that they will see the information that is similar or different for accuracy and reliability of the information.

e) Time limit: Observers should determine the time of observation. It is because when the time changes, there may be some factors that change which affects the thoughts, attitudes, and behaviors that determine the exact time period to get the correct information as current.

3) Analysis and Brainstorming are what happen after being aware and observing consisting of.

a) Information: Once the information has been obtained, the observers must transform information into knowledge that is accurate and reliable.

b) Brainstorming: Good information must go through the analysis and brainstorming process, Therefore, in order to make the analysis of data diverse, it should result from learning and analyzing data together as a group. Therefore, brainstorming causes the exchange of knowledge in many dimensions.

c) Discovering New Knowledge: When people learn contents, they must be able to brainstorm with other people in the group. To get new knowledge, they can think about the knowledge to develop the work.

4) Practicing is the development of action skills by themselves through actual practice consisting of 3 phases:

a) The cognitive phase is a step that tells the skills and knowledge of relevant theories which instructors should provide information to students in various areas, including what to do and what you need to see and avoid. For example, you need to know the process that requires for work, what precautions should be taken, and the desired standard level. Students should pay special attention to analyzing various errors. This understanding should be done in a short period of time.

b) The associative phase is an action to get behavior in the correct format. Skills can be achieved when operating. Incorrect errors or behaviors should be limited. In this process, instructors should arrange activities for students in various areas, including demonstrating skills to practice. This allows students to mimic skills, practice that skill with real situations and simulations, provide knowledge and information about the effects of skills, and provide advice and assistance as needed. This step should be started from the cognitive stage and should be contacted periodically.

c) The autonomous phase is a process that is fast and accurate. The opportunity to make a mistake will not happen. Skills increased will lead to the expertise. It is more automated at this stage, and we call the expert stage which requires a lot of practice. Training in this stage is considered to have reached the final level of the taxonomy in the range of skills. In this stage, the instructor should arrange activities for the students to do in various areas, including more skill training, learning how to overcome stress, increasing speed and accuracy, and achieving the desired standard experience at this stage. Each student may show different achievements. This difference often depends on the abilities, interests, habits, emotions and perseverance of the learner. The characteristics of graduate practitioners include practice, application of theories, application of academic and professional knowledge, and product creations [10].

5) Checking and Improvement is a process after the above process is completed consisting of:

a) Opinion: Learners use what they have practiced in exchange for learning to open their eyes and express opinions.

b) Learning Exchange: When commenting, they will exchange the knowledge and see more information in various dimensions both learners with learners and learners with the instructor.

c) Providing Opportunities: The instructor is responsible for ensuring that the learner's method provides accurate results. When finding a defect, they need to give advice and give students the opportunity to improve their results to the best.

6) Action consisted of:

a) Behavior Changing: The learners change their behavior from what they have learned and can apply this skill to learning in other contents. It stimulates the students' feelings, attitudes, and responses to expressive behaviors.

b) Application of academic knowledge: The learners can apply to use the academic knowledge with other subjects.

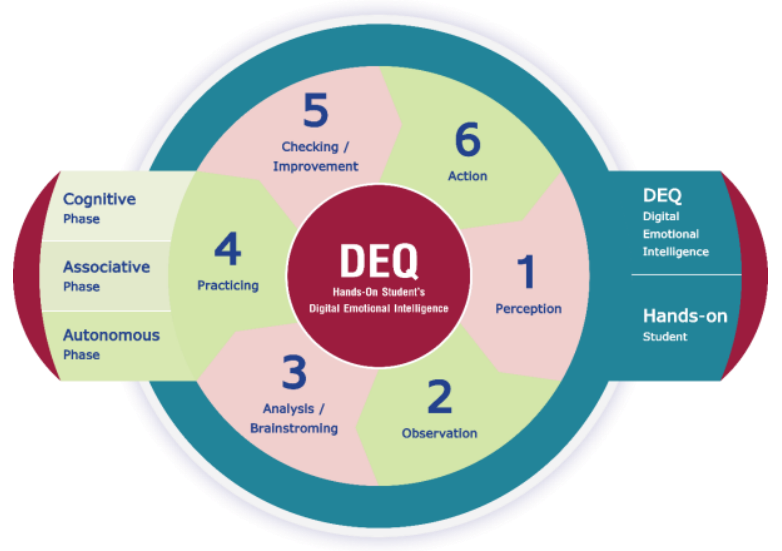

Fig. 1. The social-emotional learning process to develop practicing skills for hands-on students.

\section{B. Research Result}

According to literature review related to social-emotional learning, the results of the assessment of the suitability of the social-emotional learning process by 21 experts are shown in Table II.

TABLE II: THE RESULTS OF THE SUITABILITY OF THE SOCIAL-EMOTIONAL LEARNING PROCESS

\begin{tabular}{|l|l|l|l|}
\hline \multicolumn{1}{|c|}{ Items } & Mean & S.D. & Suitability \\
\hline 1. Perception & 4.52 & 0.51 & Highest \\
\hline 1.1 Sensory Perception & 4.67 & 0.48 & Highest \\
\hline 1.2 Explaining Perceived & 4.81 & 0.40 & Highest \\
\hline 2. Observation & 4.62 & 0.50 & Highest \\
\hline 2.1 Certain Goals & 4.86 & 0.36 & Highest \\
\hline 2.2 Discretion & &
\end{tabular}




\begin{tabular}{|l|c|c|c|}
\hline \multicolumn{1}{|c|}{ Items } & Mean & S.D. & Suitability \\
\hline 2.4 Observations & 4.57 & 0.51 & Highest \\
\hline 2.5 Time Limit & 4.24 & 0.44 & High \\
\hline 3. Analysis and Brainstorming & 4.67 & 0.48 & Highest \\
\hline 3.1 Information & 4.71 & 0.46 & Highest \\
\hline 3.2 Brainstorming & 4.29 & 0.46 & High \\
\hline $\begin{array}{l}\text { 3.3 Discovering New } \\
\text { Knowledge }\end{array}$ & \multicolumn{5}{|l|}{} \\
\hline 4. Practicing & \multicolumn{3}{|l|}{} \\
\hline 4.1 The cognitive phase & 4.90 & 0.30 & Highest \\
\hline 4.2 The associative phase & 4.86 & 0.36 & Highest \\
\hline 4.3 The autonomous phase & 4.76 & 0.44 & Highest \\
\hline 5. Checking and Improvement & 4.62 & 0.50 & Highest \\
\hline 5.1 Opinion & 4.71 & 0.46 & Highest \\
\hline 5.2 Learning Exchange & 4.33 & 0.48 & High \\
\hline 5.3 Providing Opportunities & 4.48 & 0.51 & High \\
\hline 6. Action & 4.95 & 0.22 & Highest \\
\hline 6.1 Behavior Changing & 4.64 & 0.44 & Highest \\
\hline $\begin{array}{l}\text { 6.2 Application of Academic } \\
\text { Knowledge }\end{array}$ &
\end{tabular}

Table II shows the results of the suitability of the social-emotional learning process. The overall is appropriate at the highest level $($ Mean $=4.64$, S.D. $=0.44)$. When considering each steps, it was found that the perception step consisted of sensory perception and explaining perceived, and they are appropriate at the highest level. The observation step consisted of certain goals, discretion, notes, observations, and time limit. Observations is appropriate at the highest level, and time limit is appropriate at the high level. The analysis and brainstorming step consisted of information, brainstorming, and discovering new knowledge. Brainstorming is appropriate at the highest level, and discovering new knowledge is appropriate at the high level. The practicing step consisted of the cognitive phase, the associative phase and the autonomous phase, and they are appropriate at the highest level. The Checking and Improvement step consisted of opinion, learning exchange, and providing opportunities. Learning exchange is appropriate at the highest level, and providing opportunities is appropriate at the high level. Lastly, the action step consisted of behavior changing and application of academic knowledge. Behavior changing is appropriate at the high level, and application of academic knowledge is appropriate at the highest level.

\section{CONCLUSION}

From the study of documents and research related to social-emotional learning, it was found that the social-emotional learning process to develop practicing skills for hands-on students consisted of six steps: 1) perception is divided into sensory perception and explaining perceived, 2) observation is divided into certain goals, discretion, notes, observations, and time limit, 3 ) analysis and brainstorming is divided into information, brainstorming, and discovering new knowledge, 4) practicing is divided into cognitive phase, associative phase, and autonomous phase, 5) checking and improvement is divided into opinion, learning exchange, and providing opportunities, and 6) action is divided into behavior changing and application of academic knowledge.

From In-depth interview with 21 experts in three different areas (i.e., in learning and teaching, information technology, and mass communication technology terms), the results of the suitability evaluation revealed that the social-emotional learning process model with mixed reality for the hands-on students was at the highest level, and these accord with [19], A Curriculum Development to Enhance Social and Emotional Learning for Teacher Students. The social-emotional learning consisted of six steps: 1) Perception and observation, 2) Systematic analysis, 3) Generating proper practice, 4) Action, 5) Evaluation and improvement, and 6) Reinforcement. Therefore, the social-emotional learning process to develop practicing skills for hands-on students of Rajamangala University of Technology Thanyaburi provides opportunities and time support.

\section{CONFLICT OF INTEREST}

The authors declare no conflict of interest.

\section{AUTHOR CONTRIBUTIONS}

Kridsanapong Lertbumroongchai studied literature review, design the Social-Emotional Learning Process and wrote a paper. Kobkiat Saraubon created the evaluation form and collected and analyzed the data and Prachyanun Nilsook had approved the final version.

\section{ACKNOWLEDGMENT}

The Social-Emotional Learning Process to Develop Practicing Skills for Hands-on Students has successfully completed with a great support from Advisor: Kobkiet Saraubon (Ph.D.), Associate professor Prachyanun Nilsook, and Associate Professor Panita Wannapiroon at King Mongkut's University of Technology, North Bangkok, Thailand. The researcher also would like to sincerely thank all experts who have put their effort in evaluating and providing useful advices on the development of the learning process. Finally, the researcher like to sincerely thank Faculty of Mass Communication Technology, Rajamangala University of Technology Thanyaburi, Thailand.

\section{REFERENCES}

[1] J. Bellanca and R. Brandt, 21st Century Skills: Rethinking How Students Learn, IN: Solution Tree, 2010.

[2] V. Panich, The Way to Create Learning for Students in the 21st Century, Bangkok: Sodsri-Saridwongso Foundation, 2012.

[3] KidsMatter, Information for Parents, Carers \& School Staff: Component 2 SOCIAL and Emotional Learning for Students, 2011.

[4] CASEL, Effective Social and Emotional Learning Programs, 2015.

[5] ASCD, Social and Emotional Learning Opportunities for Massachusetts, Lesson for the Nation, 2015.

[6] A. Shirley, 5 Charts That Explain the Future of Education, 2017.

[7] CASEL, What is SEL? 2017.

[8] Ministry of Education Singapore, Social and Emotional Learning, 2017.

[9] Plan International, Life Skills Guide, Bangkok: Righttoplay, 2017.

[10] C. Papattha, P. Nilsook, and N. Jeerungsuwan, "Model for development of mass communication technology graduates' desired characteristics based on Thai Qualifications Framework for Higher Education," International Journal of Information and Education Technology, vol. 5, no. 6, pp. 397-402, 2015.

[11] P. Powell, Digital Emotional Intelligence, 2017. 
[12] A. K. Johnson et al., "Using participatory scenarios to stimulate social learning for collaborative sustainable development," Ecology and Society, vol. 17, no. 2, p. 9, 2012.

[13] C. Pahl-Wostl et al., "Social learning and water resources management," Ecology and Society, vol. 12, no. 2, p. 5, 2007.

[14] M. Mutahara et al., "Social learning for adaptive delta management: Tidal river management in the Bangladesh delta," International Journal of Water Resources Development, 2017.

[15] M. R. Cubas et al., "Components of social learning theory in a tool for teaching nursing," Rev. Bras. Enferm., vol. 68, no. 5, pp. 623-629, 2015.

[16] GSB Generation, 4 Ways to Develop Emotional Intelligence, 2017.

[17] D. Goleman, Five Steps to Develop Emotional Intelligence, 2016.

[18] M. Cianca and S. Cleverley-Thompson, Seven Steps to Emotional Intelligence, 2014

[19] P. Thaithani and S. Termsinsuk, "A curriculum development to enhance social and emotional learning for teacher students," Far Eastern University Academic Review, vol. 10, no. 3, pp. 173-186, 2016.

Copyright $\odot 2020$ by the authors. This is an open access article distributed under the Creative Commons Attribution License which permits unrestricted use, distribution, and reproduction in any medium, provided the original work is properly cited (CC BY 4.0).

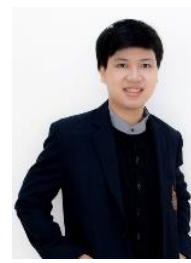

Kridsanapong Lertbumroongchai is a Ph.D. candidate in Division of Information and Communication Technology for Education, Faculty of Technical Education, King Mongkut's University of Technology North Bangkok (KMUTNB), Thailand. He obtained his master degree M.S.Ind.Ed. in learning technology and mass communication from Faculty of Education Technology, King Mongkut's University of Technology Thonburi (KMUTT), Thailand, and the bachelor degree B.Sc. in applied computer science-multimedia, from King Mongkut's University of Technology Thonburi, Thailand. His research interested in multimedia, digital media, mass communication technology, and information communication technology.

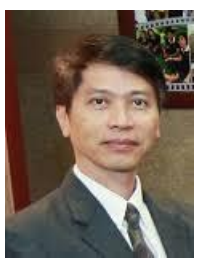

Kobkiat Saraubon is an asst. prof., lecturer, and researcher, in Department of Computer and Information Science, King Mongkut's University of Technology North Bangkok (KMUTNB), Thailand. He received his bachelor degree in mechanical engineering (first-class honors), master degree in computer science and Ph.D. in information and communication technology for education. His research area includes the IoT, embedded system, data science, machine learning, robotics, sensor technology, mobile and wearable applications development, and security.

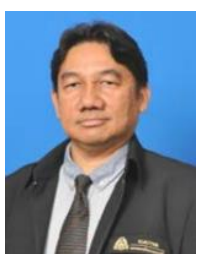

Prachyanun Nilsook is a professor at the Division of Information and Communication Technology for Education, Faculty of Technical Education, King Mongkut's University of Technology North Bangkok (KMUTNB), Thailand. He currently works in the field of ICT for education. He is a member of the professional society, the Association for Educational Technology of Thailand (AETT) 